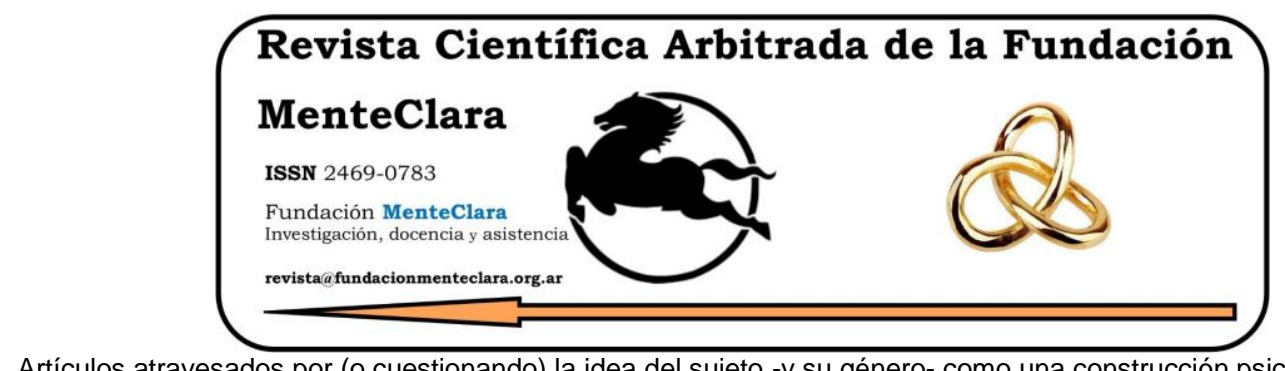

Artículos atravesados por (o cuestionando) la idea del sujeto -y su género- como una construcción psicobiológica de la cultura. Articles driven by (or questioning) the idea of the subject -and their gender- as a cultural psychobiological construction.

Vol. 5 (2020), enero-diciembre

ISSN 2469-0783

https://datahub.io/dataset/2020-5-e175

\title{
CONSTRUCCIÓN DEL PODER EN JUAN MANUEL DE ROSAS
}

\section{CONSTRUCTION OF POWER IN JUAN MANUEL DE ROSAS}

Analia Verónica Losada analia_losada@yahoo.com.ar Universidad de Flores, Argentina

Cómo citar este artículo / Citation: Losada A. V. (2020). "Construcción del Poder en Juan Manuel de Rosas". Revista Científica Arbitrada de la Fundación MenteClara, Vol. 5 (175). DOI: https://doi.org/10.32351/rca.v5.175

Copyright: (C) 2020 RCAFMC. Este artículo de acceso abierto es distribuido bajo los términos de la licencia Creative Commons Attribution 4.0 International License (CC BY 4.0). Recibido: 10/11/2020. Aceptado: 14/11/2020 Publicación online: 16/11/2020

Conflicto de intereses: Ninguno que declarar.

\section{Resumen}

Buscando analizar las dinámicas y la persona de Juan Manuel de Rosas en un marco socio histórico argentino, frente a las dificultades de la construcción de un orden legal que, entre otros contrafuertes, se inscribe la correspondencia de Rosas a Facundo Quiroga. Mediante el análisis epistolar se buscó encontrar al hombre detrás del poder, donde se estima la existencia de otro Rosas: el que ama a los niños, el que posee afecto recíproco con ciertos indios y prójimos que le sirven, el que inquiría la bendición de su madre, el cónyuge de Encarnación, el progenitor de Manuelita y el abuelo de sus nietos ingleses. Se hallaron otros roles por los que no se recuerda a la figura de Rosas como creador de un dispensario en su estancia de Palermo para sus peones y amigos sin patrimonios. La perspectiva observada da cuenta de afectividad asimismo de amor hacia su Patria, sin embargo de corte primaria, instintiva y violenta, en analogía de firmeza, carácter e ímpetu.

\section{Abstract}

Seeking to analyze the dynamics and the person of Juan Manuel de Rosas in an Argentine socio-historical framework, facing the difficulties of the construction of a 
legal order that, among other buttresses, is inscribed in the correspondence from Rosas to Facundo Quiroga. Through the epistolary analysis, it was sought to find the man behind the power, where the existence of another Rosas is estimated: the one who loves children, the one who has reciprocal affection with certain Indians and neighbors who serve him, the one who inquired the blessing of his mother, Encarnacion's spouse, Manuelita's father and the grandfather of her English grandchildren. Other roles were found for which the figure of Rosas is not remembered as the creator of a dispensary in his stay in Palermo for his peons and friends without assets. The observed perspective shows affectivity as well as love towards their country, however primary, instinctive and violent, in analogy of firmness, character and impetus.

Palabras Claves: Juan Manuel de Rosas; Poder; Politica Argentina

Keywords: Juan Manuel de Rosas; Power; Argentine Politics 


\section{El contexto y la persona de Juan Manuel de Rosas}

En un contexto particular de la historia argentina, frente a la carestía de la construcción de un orden legal que, entre otros contrafuertes, se basó en un proceso político y económico de expansión de la frontera, con poblamiento, ocupación, distribución e incorporación de las nuevas tierras al proceso productivo se inscribe la epístola de Juan Manuel de Rosas a Facundo Quiroga (Reguera, 2006). En el mundo, Francia atravesaba su Revolución donde, señala Ibarguren (1938), las metrópolis europeas se hallaban en confusión, temor y consternación, instancias que dejaban pendiente el rol de la iglesia católica, denotando una revisión del absolutismo y del feudalismo.

Juan Manuel de Rosas nació el 30 de marzo de 1793 en Buenos Aires de dos de los grupos familiares más significativos y adinerados de ese periodo, propietarios de estancias y de un capital social poderoso. Su linaje paterno devenía de los Ortiz de Rozas y por la rama familiar materna de los López Osornio. Su padre, León Ortiz de Rozas, se desempeñó como militar, cadete del ejército español, teniente del Regimiento de Infantería de Buenos Aires, administrador de los bienes de la Corona y Capitán Real. Su madre fue Agustina López Osornio. Su abuelo materno, Clemente López Osornio, se desenvolvió como sargento mayor de milicias, comandante de fronteras y hombre de recursos en Magdalena, potentado de la estancia el Rincón de López, que luego heredo su hija Agustina y sentó el hogar conyugal donde se criaron Juan Manuel de Rosas y sus nueve hermanos. Se destaca que otros diez hijos del matrimonio de Agustina y León murieron (Ibarguren, 1938) (Ramos Mejía, 2001) (Reguera, 2006). 
El advenimiento de la familia paterna Ortiz de Rozas a Buenos Aires, procedentes de España, se remonta al año 1742, a la vez que la familia materna López Osornio guarda su arribo al año 1680 (Ramos Mejía, 2001) (Reguera, 2006).

Desde pequeño Juan Manuel se mostró como voluntarioso y dominante. En su pubertad y bajo los elogios de Liniers y el mando de Alejo Caxtex manejó un cañón en la Reconquista de Buenos Aires, formando parte del cuarto escuadrón denominado Migueletes. Don León y Doña Agustina recibieron esquelas de felicitación dada la conducta valerosa de Juan Manuel (Ibarguren, 1938). Su autodeterminación en una conflictiva familiar llevo a Rosas a cambiar su apellido, limitando a Rosas, eliminando el Ortiz y cambiando la letra s en vez la de $z$, en Rozas.

Diez años después de la Revolución de Mayo cuando transcurría 1820, Rosas era un joven estanciero. Jóvenes contemporáneos a Rosas bregaban por la libertad y la independencia, aunque Juan Manuel parecía ajeno a esas luchas desempeñándose en tareas rurales de estancia, como indiferente o prescindente de los hechos de la época. Aunque Rosas como estanciero organizaba un régimen organizativo cuasi militar, en vista a las posibles amenazas casi permanentes de invasión de los salvajes (Ibarguren, 1938).

Es decir que Rosas, siendo aún un joven lucho con ahínco en contra de los ingleses defendiendo su ciudad, observando que extranjeros colocaban en peligro la vida, el patrimonio y los intereses de los conquistados y actuó expulsando al agresor, para restaurar la paz y el régimen establecido. Por el contrario en la Revolución de Mayo parece 
que Rosas porta de un espíritu contenido de arrebatos para los ideales revolucionarios de liberación (Ibarguren, 1938).

En paralelo, en 1813, contrajo enlace con Encarnación Ezcurra, con una marcada oposición de su madre. Productos del matrimonio de Encarnación y Juan Manuel nacieron Juan Bautista, el 30 de julio de 1814, María, nacida el 26 de marzo de 1816 y fallecida al día siguiente, y Manuela el 24 de mayo de 1817. Para mediados de la década del 20, se halla a Rosas con una sólida madurez, unido en matrimonio y con una fortuna de más de tres millones (Gálvez, 1954).

A fines de 1825 el gobernador Las Heras comisionó a Rosas para asegurar la paz con las tribus, en el marco de temor de que los brasileros se apoderasen de Patagones y del algún modo incitasen a los indios a invadir la campaña sur de Buenos Aires. El gobierno de la época sostenía que Juan Manuel de Rosas se constituía como la persona apta para pacificar en forma duradera las cuestiones con los indios fronterizos. En 1826, el 10 de abril, Rosas comunico al gobierno nacional de reciente organización y presidido por Rivadavia del resultado positivo de su misión y a la vez describió las dificultades y detalló una serie de requerimientos entre los que se destacaron el pedido de nombramiento de un comisionado permanente que asegurara el cumplimiento de las promesas dadas a las tribus completar las acciones de pacificación. Pareciera que el gobierno nacional se hallaba inmerso en otras preocupaciones e ignoro a las alocuciones de Rosas y algunos caciques sintiéndose estafados y engañados se unieron a tribus ranqueles e invadieron la provincia. Rosas mostró reproches frente al gobierno y dio su espalda al régimen de Rivadavia en un clima nacional de tempestad de guerra, conflictividad, 
pasiones políticas y disoluciones. Pareciera que toda disolución nacional habíase presentado, cayó Rivadavia y no se vislumbraba una Nación. A la vez las provincias disgregadas se sumergieron en anarquías y guerras (Ibarguren, 1938). Rosas desprecia a Rivadavia, mofándose de su gobierno dirigido, según su parecer, a la clase elevada y prescindente del pueblo y del campesino (Gálvez, 1954).

Pareciera que Rivadavia había herido la susceptibilidad porteña en el amor a la provincia y al sentimiento religioso que dominaba por ese tiempo la sociedad, sublevando los porteños ante la federalización de Buenos Aires y la capitalización de la ciudad. En respuesta a estas dos controversias, Rosas fue agente de protesta contra la politica unitaria en la campaña bonaerense en tanto que el sentimiento religioso se sintió atacado por la acción liberal de los unitarios (Ibarguren, 1938).

Rosas representa en el pasado argentino un espíritu realista y conservador. Se constituyó como el brazo irresistible de la reacción conservadora y materialista que interpretó el realismo político del medio circundante. A la vez Rosas encarnó la imagen del caudillo que ubica a una sociedad convulsionada por la Revolución y lleva adelante su gobierno con su acción personal como patrón predominante (Ibarguren, 1938).

La carta de Rosas a Quiroga del 20 de diciembre de 1834 parece inhabilitar las investigaciones que lo posicionan como populista, describiendo en la epístola una descripción de la construcción del poder. El contexto del escrito denota una situación de precariedad en una época de la que es plausible observar un despotismo. La epístola de referencia 
da cuenta de la idea de poder en Rosas, cuya concepción alude a un poder absoluto. Rosas representa la autoridad en términos absolutos, donde pareciera que la plebe no presentaba ningún rol. El gobernador Rosas se constituyó como una figura de autoridad, compuesto de elementos ritualistas y con cierta legitimidad que le confiere el poder. Un mes antes de la fecha de la epístola, el 18 de noviembre de 1834 en Argentina se funda la provincia de Jujuy dividiéndose de la provincia de Salta, siendo que Jujuy es la última de las catorce provincias argentinas que continuarian sin modificaciones hasta mediados del siglo veinte.

Ante el triunfo del federalismo en el interior y siendo vencidos Lamadrid y Arenales, se constituye Facundo Quiroga como héroe de los vencedores. Juan Facundo Quiroga era una figura representativa del gaucho del interior de país, con una personalidad impetuosa, agreste, explosiva e impulsiva. Quiroga, hijo del capitán de milicias Prudencio Quiroga, nació en La Rioja en 1788. Estuvo preso, fue soldado condecorado y a la vez recibió la exhortación del General San Martin para hacer la paz con sus adversarios (Ibarguren, 1938).

Sarmiento (1960) muestra en su obra Facundo de 1845 la vida de Don Juan Facundo Quiroga, desarrollando una observación sátira de la cultura argentina, encarnada en hombres como Juan Facundo Quiroga, principalmente en San Juan. Quiroga se conducía como caudillo, un jefe de masas populares armadas, que según la interpretación de Sarmiento eran enunciaciones de una forma de gobierno bárbara, sintoma de los conflictos culturales de la época. 
En tanto pareciera que el sello y firma del acercamiento y vinculación entre Quiroga y Rosas fue dado por Lamadrid. Rosas que apreciaba a Lamadrid se dirigió a Quiroga solicitándole que no se le perjudique a Lamadrid en el tránsito a Buenos Aires, donde se reuniría con su familia y sería asistido en sus dolencias, desde la provincia de Salta. La colaboración en ello inició una relación entre dos hombres con marcadas diferencias, desde su aspecto físico hasta en sus modismos, pero con la semejanza de la capacidad de ambos de la interpretación del alma campesina y de la protesta frente a las injusticias que percibian del momento (Ibarguren, 1938).

La hostilidad frente a la Constitución unitaria y el levantamiento de las provincias frente a las politicas de corte unitario influyeron en la caída del Gobierno de Rivadavia y disolvieron del Gobierno Nacional. Siendo Vicente López y Planes presidente provisorio por un brevísimo tiempo nombra a Rosas el 14 de julio de 1827 como Comandante General de las milicias existentes en la campaña de la provincia de Buenos Aires. Por entonces Dorrego le encomienda continuar las tareas de paz y tranquilidad en relación con los indios, y le solicita a la vez preparar un plan de extensión de las fronteras del sur con un asentamiento y puerto en Bahía Blanca. Rosas se ocupó de tales encomendaciones con un gran espíritu organizativo y con coordinación militar asociada a la participación de los hacendados (Ibarguren, 1938).

Las cosas cambiarian y Rosas, resentido, se distanció de Dorrego puesto que sostuvo que el gobierno desoía sus propuestas y proyectos y aunque presentó su renuncia esa dimisión no fue aceptada. La política 
de Dorrego sufría en la época de desprestigios y era foco de críticas (Ibarguren, 1938).

Hacia 1829 Rosas y Lavalle firmaron el Pacto de Cañuelas, que incluía el llamado a elecciones, en la lista única el consenso llevaría al candidato Félix de Álzaga. Con elogios patrióticos hacia Rosas Lavalle presentó el tratado. La fase unitaria postulo la candidatura de Carlos María de Alvear, y con nuevas dificultades Lavalle es llevado a un nuevo tratado, el pacto de Barracas, del 24 de agosto, donde se designó gobernador a Juan José Viamonte. Éste convocó a la legislatura depuesta por Lavalle, allanándole a Rosas la vía al poder. La Legislatura de Buenos Aires proclamó a Juan Manuel de Rosas como Gobernador de Buenos Aires el 6 de diciembre y le brindó el grado de "Restaurador de las Leyes e Instituciones de la Provincia de Buenos Aires", dejando constancia que poseía facultades ordinarias y extraordinarias que entendiera necesarias, hasta el nuevo encuentro de la nueva legislatura. El primer gobierno de Juan Manuel de Rosas fue una acción de orden y progreso entre 1829 y 1832, aunque no contó con el apoyo incondicional de toda la población que Rosas consideraba requerido para su función (Gálvez, 1954). Un interludio entre su próximo gobierno fue llevado adelante por Juan Ramón Balcarce. Su segundo gobierno comenzó en el año 1835.

Puede interpretarse que la construcción de poder de Juan Manuel de Rosas se cimienta en la organización de un sistema de lealtades, siendo la guerra una de las posibles dimensiones y las facciones elementos de organización. Esta edificación se alza en notables con solidaridades politicas y escisiones que parecieran insoslayables "nosotros y ellos". La concepción política de Rosas parece encontrar su justificación en el 
conflicto. De alguna forma independientemente de si Rosas lo era, su coalición política era de corte federal.

Bonaudo alude a un centralismo en la construcción del estado, siendo que esta representación cultural de la politica posibilita vislumbrar la edificación política de la época (Bonaudo, 1999). Rosas realizaba múltiples referencias a la realidad norteamericana, mostrando de algún modo sus lecturas, aunque no se presentaba como un hombre leído. Rosas no creía necesitar de intelectuales para su construcción de poder en el desarrollo de la República, aunque parece aclarar bien a quienes no necesita con alusiones claras hacia aquellos que identifica como agitadores y ahuyentadores de la paz, la tranquilidad y el orden.

La base de su poder era sin dudas Buenos Aires y a la vez el poder de Buenos Aires se hallaba estrechamente ligado a los recursos de la Aduana. En la mencionada epístola Rosas manifiesta alusiones a cuestiones de índole financiera y económica, y a la administración de estos recursos. Buenos Aires prospera en la época de Rosas.

E1 legado de Rosas exhibe una clara adherencia a obedecer, un modo de disciplinamiento social, un orden y periodo entre paréntesis de la construcción nacional donde el realismo es puro y el poder era concebido en términos absolutos. 


\section{Correspondencia de Rosas a Quiroga, 20 de diciembre de 1834}

Rosas destina la carta a Quiroga desde la Hacienda de Figueroa citada en San Antonio de Areco en la Provincia de Buenos Aires el día 20 de diciembre de 1834.

Este despacho, con la restricción de las dificultades y conflictos entre los gobernadores de Tucumán y Salta, ha sido publicado en el número 4735 en La Gaceta Mercantil del día 18 de abril de 1839. Posteriormente Alberdi la incluyó en el periódico El Nacional de Montevideo en su número 124, en el mismo día de publicación. La misma esquela fue republicada en el número 4846 del 26 de agosto del mismo año de La Gaceta Mercantil, con posterioridad al asesinato de Quiroga. En el número 5974 del mismo diario del día 26 de agosto de 1843, es decir cinco años más tarde, volvió a publicarse. Tuvo nuevas replicas en el marco del pronunciamiento de Urquiza en el número 8204 del 15 de marzo de 1851 en La Gaceta Mercantil, en el Diario de Avisos en su número 647 del 21 de marzo y en el Aviso Americano número 26 del 20 de septiembre de 1851.

Al respecto de la publicación señala Barba (1958) que en la primer publicación en 1839 Alberdi se mostró crítico de los postulados de Rosas, señalando que Rosas no promovía una Constitución para la República Argentina. Se refirió en duros términos considerándolo dictador y tirano. En referencia a la réplica de 1851, el periódico de Montevideo La Semana dirigido por José Mármol, se señala la repetición de símiles argumentos de Rosas y considerándolos de estorbo en una concepción constitucionalista, en el contexto de la Asamblea General y su 
reproducción en la situación de Entre Ríos a la fecha de la publicación. Asimismo El Iris Argentino, de Paraná fechado el 7 de agosto postula la epístola como un documento indigesto.

La Hacienda Figueroa se encuentra ubicada en el camino real al Alto Perú, vía entre San Antonio de Areco y Luján, contigua a la localidad de Azcuénaga y en las cercanías de la confluencia de los arroyos de Suero y Giles. La Hacienda de Figueroa, territorio conocido como estancia "La Merced", tiene su emplazamiento dentro de la jurisdicción del Partido de San Andrés de Giles desde el dictado de la Ley N 541 del 24 de octubre de 1864, reglamentada al año siguiente, por la cual se fijó la delimitación territorial de los distritos bonaerenses de la campaña, situados al norte del Río Salado (Moreno, 1989).

Las cartas poseen interlocutores, en este caso Quiroga gozaba de una relevancia en la politica argentina. Rosas en 1834 dirige la epístola a Don Facundo Quiroga, refiriéndose al caudillo como querido compañero. Juan Facundo Quiroga ha sido un caudillo argentino que se desempeñó provisionalmente como gobernador de La Rioja. Quiroga presentó un papel notable por esos años a favor de una organización nacional y de la constitución de una Constitución Nacional. Rosas remite la carta tres meses antes del asesinato de Quiroga (Goldman, 1993).

Rosas inicia su texto en relación con las contrariedades de Tucumán y Salta y las desavenencias acaecidas entre ambos gobiernos podrian haberse ligado al gobernador de Jujuy, Pablo Alemán. En relación con este militar uruguayo señala que habría sido recibido por el Sr. Alejandro Heredia en la provincia de Tucumán. Instalado en esa provincia se 
constituyó en clara oposición a Pablo Latorre, caudillo por Santiago del Estero. Al respecto señala Rosas, que la operatoria no se constituyó fructífera para Alemán por tanto fue aprendido y conducido a Salta, luego del tránsito fallido en la frontera de Rosario. Posteriormente se retiró bajo fianza y no se reintegró a la provincia. En línea con los acontecimientos Latorre mostró su desagrado y disconformidad y los unitarios, a los que ubica como lobos al acecho, intentaron beneficiarse con la situación y reestablecer su imperio, en términos de Rosas. Al respecto Rosas expresa su opinión negativa a los reclamos indemnizatorios de Alejandro Heredia, en concepto de daños y perjuicios. Rosas postula que más que basarse sus reclamos en hechos, los elementos son conjeturas e indicios, por tanto deberian no más que desestimarse. Rosas refiere a la solicitud de compensación económica señalando que los negocios de Estado a Estado no deberían dirimirse a través de leyes que rigen un país para los asuntos entre particulares, sosteniendo que el principio que regian dichas leyes aludia a circunstancias y razones situadas en una forma contextualizada. Señala Rosas que además de la valoración judicial debe repulsarse en términos políticos la solicitud de indemnización injustificada según su parecer con basamentos en indicios y conjeturas no en hechos tangibles. Reclamos tales podrían perjudicar a la relación entre ambas provincias y gestar, en palabras de Rosas, un germen de odio inextinguible y grandes males a la República. A la vez avanza señalando que si alguno de los contendientes hubiera atraicionado abiertamente la causa Nacional de la Federación se debería procederá dejar el puesto (Barba, 1958).

A posteriori de las referencias a los conflictos y sus formas dirimirlos Rosas postula su manifestación en torno a la generalización de la necesidad de la Constitución. Señala los basamentos de su proceder los 
hechos, los escándalos acontecidos, el estado peligroso en el que ubica a la República al momento de la epístola a Quiroga. Por tanto se pregunta si el remedio es precipitar una Constitución del Estado (Barba, 1958).

Interpela a Quiroga, Rosas y señala que nadie más que ellos mismos podrian hallarse más persuadidos acerca de las necesidades de una Constitución Nacional en el marco de un Gobierno General, aportando respetabilidad a la República (Barba, 1958).

Rosas señala que observa la necesidad de un sistema federal, señalando la ausencia de elementos para un gobierno de unidad. Expone en la carta hacia el caudillo riojano que una facción de hombres ignoró esta necesidad eliminando los recursos y los medios, generando desánimos y descarriando opiniones, sembrando disociaciones y lo único que parece ser una posibilidad a este lastimoso estado, según la expresión de Rosas, es crearlo todo de nuevo. Alude a una organización primero por sobre lo pequeño y luego en fracciones de bandas de modo tal que a posteriori un sistema general pueda abrazarlo todo. En este sentido alude a que una República Federativa, puede ser quimérica y desastrosa en la medida que no se componga de estados sumamente organizados en sí mismos, con una perspectiva de cada uno soberana e independiente y la representación del poder general posibilita llevar la voz de los estados confederados en sus relaciones con naciones del extranjero. Por tanto Rosas le expone a Quiroga que si en el interior de cada uno de los estados no hay elementos de poder para sostener su respectivo orden la creación de un Gobierno General representativo no aporta más que una suma de agitación en la Republica replicando 
cualquier agitación parcial en el todo, bajo del señalamiento metafórico que un incendio en una parte se derramara en el resto (Barba, 1958).

Asimismo Rosas efectúa una búsqueda analógica con lo acontecido en los Estados Unidos América, pronunciando que la República del Norte América no ha incorporado nuevos pueblos en la Confederación a posteriori de su independencia, manteniéndolo sin representación en clase de estados, considerándolos como adyacencias de la República (Barba, 1958).

Rosas realiza una descripción de lo que a su visión acontece contextualmente: los pueblos atraviesan estados de agitación, con contaminación de unitarios, de logistas, de aspirantes, de agentes secretos de otras naciones y de las grandes logias que acechan a Europa. Por tanto al parecer del gobernador no existirian posibilidades de tranquilidad y calma al celebrar los pactos de la Federación, siendo esto un requisito sine qua non en el estado de pobreza en que las agitaciones políticas han ceñido a todos los pueblos (Barba, 1958).

En relación con los recursos económicos y financieros Rosas alude a con qué fondos pueden afrontarse los gastos de inherentes al Congreso y a la Administración General, al pago de la deuda externa, con un reclamo inminente en tanto se constituya la administración (Barba, 1958).

A la vez Rosas señala, lo que a su modo de ver se constituiría como la falta de liderazgo, ya que con las dificultades específicas que acarrea la búsqueda de gobernantes de cada provincia, como surgirán hombres 
capaces de gobernar la República. Al respecto se pregunta e interpela a Quiroga si la administración debiera ser entregada a sujetos ignorantes, aspirantes, unitarios y a toda clase de bichos. Señala que Bernardino Rivadavia, según su opinión no pudo más que sacar a un cura de la catedral y convocar a Salvador María del Carril para la cartera de hacienda. Rivadavia siendo ministro de Martin Rodríguez introduce una reforma política y social que vehiculizó un conflicto con la iglesia. Por ello ante tanto, Rosas indaga acerca de quién será el hombre de la Federación que se constituirá como capaz de llevar adelante el Gobierno General, conduciendo a un cuerpo de representantes y ministros saliendo airoso de su labor sin perder los créditos y la reputación (Barba, 1958).

Rosas esgrime que el Congreso General debe ser convencional y no deliberante, con claro asiento de las bases federales y no para dirimirlas en votación. En relación con su conformación debiera ser integrado por diputados con costas a cargo de sus respectivos pueblos, sin que otra provincia abone tales erogaciones, dejando claramente explicito que Buenos Aires lo realizo en algún tiempo y al momento no sería posible según las apreciaciones del gobernador. A la vez debiera establecerse también el lugar donde se llevaría adelante tal reunión en acuerdo con los gobiernos y la conformación de un fondo común que solvente los gastos oficiales del Congreso. El lugar advenido necesariamente aportaria a sus integrantes garantias de seguridad y respeto más allá de la ideología de cada miembro, como así también brindaría comodidad, salubridad y hospitalidad atento a que cada representante requiere de un tiempo para su alocución (Barba, 1958). 
Rosas se manifestó en relación con el lugar donde debiera ubicarse ese Congreso expresando que sí ese lugar seleccionado fuese Buenos Aires, ello concluiria en un desenlace desgraciado y funesto para Buenos Aires en sí y para la República toda. Siendo según, la opinión del gobernador, que el tiempo indicará el lugar propicio (Barba, 1958).

En términos de conformación del cuerpo del Congreso, Rosas indica que algunas características que los diputados deben poseer. Estos representantes requeririan de un federalismo a prueba, hombres moderados, prudentes y poseedores de conocimientos de la administración pública, munidos de conocimiento del interior de la República, como así también de países limítrofes y de las naciones europeas con quienes se mantienen relaciones comerciales. En tanto puntea Rosas que si las relaciones internacionales se dejasen en manos de dos o tres diputados sin las cualidades que él señala todo se convertiría en un desorden en perjuicio claro para la República con búsqueda de beneficios particulares como señala Rosas que ocurrió con Congresos previos, que finalizaron con disoluciones, hundidos en chismes y mentiras, envolviendo a la nación en dificultades mayores (Barba, 1958).

El orden de los tratamientos del Congreso para Rosas, debiera ser inicialmente la selección de un lugar donde profesar sus actividades y en segundo lugar, el desarrollo de una Constitución que erija la organización del Gobierno General, con detalle de sus miembros, participación de los Estados Federados, con alusión al lugar donde el gobierno tendrá su asiento. Así también destaca el gobernador que deben arbitrarse los 
recursos para el orden, la seguridad y la respetabilidad del país (Barba, 1958).

Pareciera de vital importancia en esta epístola la selección del lugar de funcionamiento del gobierno de la Republica. Al respecto Rosas afirma que la residencia del gobierno puede generar resentimientos, celos y rivalidades en los pueblos no elegidos para tal fin. Ejemplifica con lo acontecido en los estados norteamericanos que resolvieron el caso fundando la ciudad de Washington, como capital no perteneciente a ningún estado confederado (Barba, 1958).

Luego de la selección de la residencia gubernamental, de la organización del gobierno y sus atribuciones, las decisiones siguientes debieran, al modo de ver de Rosas, evaluar la creación de un fondo nacional permanente que cubra las erogaciones de los gastos generales, ordinarios y extraordinarios, y los pagos de deudas. Al respecto de las deudas Rosas cita la interna y la externa y especifica que más allá que las causas sean injustas o justas e independientemente del gobierno que las haya contraído el acreedor no tiene que ver con ello (Barba, 1958).

En términos de política militar, si ello no se decidiese de otro modo, cada estado federado debiera aportar un contingente de tropa proporcional a su población (Barba, 1958).

Retomando la organización nacional económica Rosas explicita en este escrito que deben analizarse los negocios del Banco Nacional y del papel moneda, en línea con la deuda nacional que presentarian con Buenos 
Aires. Detalla también, los fondos públicos, la deuda contraída con Inglaterra invertida en la guerra con Brasil, el dinero utilizado en la reforma militar, los gastos hasta 1824 devenidos de la guerra de la Independencia y las erogaciones afines que Buenos Aires ha llevado adelante para el desarrollo de congresos generales. Rosas recalca que cada estado debiera crear rentas particulares que no afectasen los intereses generales de la República (Barba, 1958).

Rosas especifica que una vez que esto lo expuesto se encuentre resuelto y allanado puede erigirse un Gobierno General y un Presidente de la República. Subraya que el país se encuentra en un estado triste y lamentable, y que en quizá dos años de asiduo trabajo apenas podría verse posibilidades de cuestiones tan importantes para la Republica (Barba, 1958).

El gobernador sostiene que algunos hombres se hallan inmersos en la tarea de alborotar pueblos para el reclamo de Constitución, siendo que para la opinión de Rosas el desorden es el modo de expresión de estos sujetos. Rosas señala que un gobierno general no une los pueblos, sino que los personifica unidos. Un gobierno de una República Federativa los representa en unión ante las demás naciones y a la vez no decide en sus cuestiones intrinsecas ni en las contiendas entre sí. El gobierno federal, entonces, es consecuencia, según Rosas, de la unión y tranquilidad, y no la causa. Dado que para Rosas no están dadas las condiciones para una Constitución, si la hubiera, se sufririan los estragos de una disolución y toda la República se convertiria en escombros. El gobernador especifica en torno a que cada provincia tiene dificultades que le son propias y a su parecer una Constitución Nacional no resolvería tal conflictiva. Este 
análisis de Rosas apunta a posibles resoluciones catastróficas que menoscabaran la reputación y mancillara sus glorias, por tanto pareciera que se debiera esperar a una verdadera oportunidad donde los resultados conduzcan a la felicidad de la Nación (Barba, 1958).

Refiere a la conducción de los estados, cuando Rosas cita la máxima de ponerse a la cabeza de los pueblos, con fines de dirigirlos a buen rumbo en su marcha, promoviendo paz y tranquilidad. Y en la medida que este espíritu pacifico reine en todos los estados se podrá negociar en buenos términos entre los gobiernos y conformar un Congreso, que no deba resolver estas conflictivas internas sino que sesione llanamente (Barba, 1958).

Rosas finaliza su epístola refiriéndose a su interlocutor Quiroga como compañero, le desea buena salud y le encomienda precaución y cuidado para sí y para salvar a sus compatriotas de los peligros que los avistan (Barba, 1958).

Gálvez (1954) señala que las cartas de Rosas demuestran franqueza. Juan Manuel de Rosas dice de los demás lo que piensa. Se expone enérgico, altivo y se indigna con frecuencia. Logra describir en la epístola lo que a su modo de ver son los peligros que acechan al país, las lealtades y deslealtades, los pasos a seguir y en qué tiempo llevar adelante las acciones. 


\section{Discusión}

En la primera mitad del siglo XIX el entramado social se hallaba multideterminada por una sucesión de intercambios, signados en un conjunto diferencial de relaciones, consanguíneas y de alianza, bajo pactos, acuerdos y obligaciones. Esta modalidad de relación exhibía vínculos de inclusión y pertenencia, que a la vez se constituirian como correlaciones de obediencia y lealtad. La sociedad argentina de la época daba cuenta de las tensiones sociales, de dominación e integración. En estas instancias cobra partido un personalismo politico tendiente a lograr el ejercicio del gobierno y del poder, más individual que de instituciones organizadas (Reguera, 2006). En este contexto surge la figura de Juan Manuel de Rosas.

Juan Manuel de Rosas encarnaba la autoridad en términos de absolutismo para su época. El principio gestáltico del todo es más que la suma de las partes se presenta en Rosas cuando señala que un gobierno general de una República de carácter federativo no ha de unir los pueblos, sino que los representa en la medida que estén unidos. En la epístola de Rosas a Quiroga se exhiben los mecanismos de construcción de poder y se alude a tiempos que a su parecer serán venideros, ya que el gobernador bonaerense consideraba que la sociedad, y la clase política especialmente, aún no se hallaba en condiciones de alinearse bajo una Constitución Nacional. Habia que esperar aún más para el devenir de la República.

Reguera (2006) describe un contexto de centralización y aglutinación politica alrededor de una figura céntrica, como Juan Manuel de Rosas. En torno a la persona protagonista y en una trama socio histórica 
delimitada se construyeron relaciones, vínculos y prácticas que hicieron plausibles la comprensión y deconstrucción de la composición de proyectos y estrategias en las que se manifestaron. En Rosas se observó una práctica encarnada con el control del poder y del gobierno.

Juan Manuel de Rosas parece referirse a una organización primero por sobre lo pequeño y luego en facciones de bandas de modo tal, que a posteriori un sistema general pudiera abrazarlo todo. En este sentido apuntaría a que una República Federativa, puede ser quimérica y desastrosa en la medida que no se componga de estados sumamente organizados en sí mismos, con una perspectiva de cada uno soberana e independiente, y con una representación del poder general que posibilitaría llevar la voz de los estados confederados en sus relaciones con naciones del extranjero. Por tanto Rosas le expone a Quiroga que si en el interior de cada uno de los estados no hay elementos de poder para sostener su respectivo orden la creación de un Gobierno General representativo no aportaría más que una suma de agitación en la Republica replicando cualquier estremecimiento parcial en el todo.

La alusión a la asignación de recursos para el Congreso y la Administración General, también podrian revelar el interés de Rosas en postergar la Constitución. A la vez, Rosas refiere un cuadro de inmadurez que no viabilizaría el surgimiento de un Congreso y una Constitución. El país aún no estaba preparado para el parecer de Rosas.

En torno al interlocutor ¿Quiroga tenía ideas claras y ordenadas o se hallaba el línea con el instinto que esbozó Sarmiento? Lo que no hay duda es de la osadía militar de Juan Facundo Quiroga. 
Asimismo se vislumbra en la figura de Rosas una contemplación hacia lo colectivo, no orientada al hombre. Su mirada parece dejar de lado los derechos, la dignidad individual o la persona humana. Rosas interpreta la Patria, la provincia, el Partido Federal o la Campaña (Gálvez, 1954).

Juan Manuel de Rosas puede concebirse en el orden. Gálvez (1954) liga el orden en Rosas y su aptitud para el mando. Incluso enlaza la obra en favor de la religión, puesto que Rosas la consideraba como el elemento ordenador de mayor eficacia. Avanza Gálvez y asevera la unión entre orden y justicia, si falta justicia no puede haber orden y viceversa. La figura de Rosas imponía orden al extremo, quizá obsesivamente y en ese fanatismo al orden, quizá también, uniformidad.

Bonaudo (1999) refiere una complejidad en la comprensión de los procesos devenidos de la caída de Rosas y la consolidación del Estado Nación. Bonaudo estima que desde la mirada de Roca la etapa verídica organizacional no comenzó con la caída de Rosas, sino que estaba por iniciarse y su asunción intentaba convertirse en un hito fundante de paz y administración, según la opinión de la autora. Trasciende a ello una ingeniería social, relacionada con transformaciones en la sociedad civil y en la comunidad politica.

La persona de Rosas logro imponerse en su contexto, constituyéndose como un político sumamente hábil en la construcción del poder. El medio circundante era caótico y otorgaba terreno fértil para una figura como la de Juan Manuel de Rosas. 
Gálvez (1954) representó a Juan Manuel de Rosas como una figura que nació para el mando, ya desde la descripción física que expone. El liderazgo que manifestó en la época se hallaba ceñido de su intuición excepcional y su astucia prodigiosa. Rosas poseía capacidad de trabajo, era buen administrador y era poseedor de un talento para conocer a los hombres, incluso para identificar sus debilidades. Señaló que su facultad dominadora fue la voluntad poderosa, constante e indoblegable. Lo describe tenaz y propagandista. Aunque el historiador revela que esta voluntad no puede más que terminar en despotismo. Su voluntad vigorosa denotaba un aspecto positivo y otro que no lo era. La faz negativa refiere una marcada disminución de la libertad, de la expresión y prensa y de los derechos de las personas. En tanto el bien se manifestaba en que un hombre de estas características parece necesario a la hora de gobernar años tan convulsos. Su voluntad parece hecha a la medida de gobernar, unificar al país y salvar a la Republica del acecho extranjero.

Al respecto Rosas dirá que si volviera a nacer y a gobernar en las mismas circunstancias procedería como procedió, invadido del sentimiento de la tarea cumplida (Gálvez, 1954).

Aunque también parece que hay otro Rosas: el que ama a los niños, el que tiene afecto mutuo con algunos indios y personas que le sirven, el que buscaba la bendición de su madre, el esposo de Encarnación, el padre de Manuelita y el abuelo de sus nietos ingleses. El creador de un pequeño hospital en su quinta de Palermo para sus peones y amigos sin recursos. En esta afectividad también hay amor hacia su Patria, aunque primario, instintivo y violento, en una relación de tenacidad, energía y vehemencia (Gálvez, 1954). 
El 14 de marzo de 1877 Juan Manuel de Rosas fallece en Southampton. Se le despide con un oficio sencillo y pobre. Solo que sobre el féretro se coloca la espada de San Martin y la bandera argentina (Gálvez, 1954).

Por lo expuesto el legado de Rosas exhibe una clara adherencia a obedecer, un modo de disciplinamiento social y un orden en un periodo entre paréntesis de la construcción nacional donde al realismo se lo observa puro y el poder era concebido en términos personales y absolutos. La época y el contexto le permitieron ser y en ese seno interpretó el patriotismo, la soberanía y la independencia de la Patria. 


\section{Referencias}

Barba, E. M. (1958). Correspondencia entre Rosas, Quiroga y López: recopilación, notas y estudio preliminar. Hachette.

Bonaudo, M. (1999). "A modo de prólogo", en Bonaudo, M. dir. Liberalismo, estado y orden burgués (1852-1880), Nueva Historia Argentina, vol. 4, Buenos Aires, Sudamericana, pp. 11-25

Gálvez, M. (1954). Vida de Juan Manuel de Rosas. Tor.

Goldman, N. (1993). Legalidad y legitimidad en el caudillismo. Juan Facundo Quiroga y La Rioja en el interior rioplatense (1810-1835). Boletín del Instituto de Historia Argentina y Americana" Dr. Emilio Ravignani", 3, 31-58.

Ibarguren, C. (1938). Juan Manuel de Rosas: su vida, su drama, su tiempo. Sopena.

Moreno, C. (1989). La Merced, Hacienda de Figueroa: pequeño testimonio de una gran historia. Colegio de Arquitectos de la Provincia de Buenos Aires, Distrito Quinto.

Ramos Mejía, J. M. (2001). Rosas y su tiempo. Emecé.

Reguera, A. (2006). Entre la ley y el azar: La trama vincular del mundo político-empresarial de la frontera sur pampeana en el siglo XIX. Prohistoria, 10, 00-00.

Sarmiento, D. F. (1960). Facundo: civilización y barbarie. Sopena Argentina. 